\section{RECONSTRUCTION OF THE MITRAL ANULUS}

\section{A ten-year experience}

Reconstruction of the mitral anulus was done in 93 patients because of extensive calcification in 24 , infective endocarditis with annular abscess in 27 , damaged anulus as a result of previous valve replacement in 36 , and rupture of the posterior wall of the left ventricle after mitral valve replacement in 6 . The reconstruction was done with fresh autologous pericardium in 30 patients, glutaraldehyde-fixed bovine pericardium in 56, and Dacron graft in 7. An appropriately tailored patch was sutured to the endocardium of the left ventricle or to fibrous skeleton of the heart, or to both. Sixty patients had had previous operation; most patients were in New York Heart Association functional class IV and 15 were in shock. The mitral valve was repaired in 10 patients and replaced in 83 . Other procedures were aortic valve replacement in 40, tricuspid valve repair in 25 , coronary artery bypass in 12, and replacement of the ascending aorta in 2. Eight patients died in the perioperative period. Postoperative complications were common. Patients were followed up from 12 to 96 months, with a mean of 30 months. There have been 18 late deaths, mostly cardiac. The actuarial survival at 5 years was $68 \% \pm 6 \%$. A total of 8 patients have required reoperation: 4 because of endocarditis, 2 because of bioprosthetic valve failure, and 2 because of patch dehiscence. The freedom from reoperation was $80 \% \pm 8 \%$ at 5 years. The freedom from patch dehiscence was $95 \% \pm 4 \%$ at 5 years. Reconstruction of the mitral anulus has been an extremely useful operative technique for patients with complex mitral valve disease. (J Thorac Cardovasc SuRg 1995;110:1323-32)

Tirone E. David, MD, Christopher M. Feindel, MD (by invitation), Susan Armstrong, MSc (by invitation), and Zhao Sun, BA (by invitation), Toronto, Ontario, Canada
$\mathrm{E}_{\mathrm{x} \text { i }}^{\mathrm{x}}$ tensive calcification of the mitral anulus, infective endocarditis of the mitral valve with annular abscess, rupture of the posterior wall of the left ventricle after mitral valve replacement (MVR), and damaged mitral anulus as a result of repeated MVRs are surgical entities associated with high operative mortality and morbidity. ${ }^{1-6}$

In an attempt to improve the results of operation in these patients we began to reconstruct the mitral anulus with a patch of autologous pericardium in $1985 .^{7-9}$ In patients with inadequate autologous peri-

From the Division of Cardiovascular Surgery, The Toronto Hospital and the University of Toronto, Toronto, Ontario, Canada.

Read at the Seventy-fifth Annual Meeting of The American Association for Thoracic Surgery, Boston, Mass., April 23-26, 1995.

Address for reprints: Tirone E. David, MD, 200 Elizabeth St., 13EN219, Toronto, Ontario, Canada M5G 2 C4.

Copyright (C) 1995 by Mosby-Year Book, Inc.

$0022-5223 / 95 \$ 5.00+0 \quad \mathbf{1 2 / 6 / 6 8 0 2 8}$ cardium because of multiple previous cardiac operations, we used glutaraldehyde-fixed bovine pericardium, and in certain patients even Dacron graft has been used as patch material with equally good results.

This report describes our experience with reconstruction of the mitral anulus during the past decade.

\section{Patients and methods}

Between June 1985 and December 1993, 93 patients aged $58 \pm 14$ years (range 17 to 86 years) underwent mitral valve surgery with reconstruction of the mitral anulus. Table I summarizes the clinical profile of these patients. Sixty patients had had at least one previous cardiac operation: 27 had had MVR $(5$ combined with coronary artery bypass grafting [CABG]), 5 had had mitral valve repair, 3 had had aortic valve replacement (AVR), 24 had had AVR and MVR ( 4 combined with CABG), and 1 had had septal myectomy because of obstructive hypertrophic cardiomyopathy. Of these 60 patients, 25 had had previous valve operations twice, 9 three times, and 2 four times. 
Table I. Clinical profile of patients

\begin{tabular}{lcc}
\hline & No. & $\%$ \\
\hline Sex & & \\
$\quad$ Male & 40 & 43 \\
Female & 53 & 57 \\
Cardiac rhythm & & \\
$\quad$ Sinus & 36 & 39 \\
$\quad$ Atrial fibrillation & 49 & 58 \\
$\quad$ Heart block & 8 & 8 \\
NYHA class & & \\
II & 8 & 8 \\
III & 21 & 22 \\
IV & 64 & 69 \\
Left ventricular ejection fraction & & \\
Grade 1 & 25 & 27 \\
Grade 2 & 56 & 60 \\
$\quad$ Grade 3 & 12 & 13 \\
Coronary artery disease & 12 & 13 \\
Previous cardiac operation & 60 & 64 \\
\hline
\end{tabular}

Table II. Indication for mitral anulus reconstruction

\begin{tabular}{lrr}
\hline & No. & $\%$ \\
\hline Extensive calcification & 24 & 26 \\
Mitral anulus abscess & 27 & 29 \\
Damaged mitral anulus* & 36 & 39 \\
Rupture of left ventricle & 6 & 6 \\
\hline
\end{tabular}

*As a result of previous operation.

Table III. Type of reconstruction and patch material

\begin{tabular}{lrr}
\hline & No. & $\%$ \\
\hline Type of reconstruction & & \\
Superior & 9 & 10 \\
Posterior & 39 & 42 \\
Circumferential & 25 & 27 \\
Aortic and mitral anuli & 20 & 21 \\
Patch material & & \\
Autologous pericardium & 30 & 32 \\
Bovine pericardium & 56 & 60 \\
Dacron fabric & 7 & 7 \\
\hline
\end{tabular}

The principal indication for operation was bioprosthetic valve failure in 26 patients, acute infective endocarditis in 27 , prosthetic mitral valve dehiscence in 11 , and symptomatic native mitral valve disease in 29. As shown in Table I most patients were in New York Heart Association (NYHA) functional class IV when operated on, and 15 of them were moribund in cardiogenic or septic shock or both these types of shock.

Table II shows the indications for reconstruction of the mitral anulus. Table III shows the type of mitral anulus reconstruction and the material used. Table IV summarizes the operative data.

Operative procedures. In 10 patients the mitral anulus was heavily calcified and the mitral valve was deemed
Table IV. Operative data

\begin{tabular}{lrr}
\hline & No. & $\%$ \\
\hline CABG & 12 & 13 \\
MVR & 43 & 46 \\
Mitral valve repair & 9 & 9 \\
AVR plus MVR & 40 & 43 \\
AVR plus mitral valve repair & 1 & 1 \\
Tricuspid valve repair & 25 & 27 \\
Prosthetic valves & & \\
$\quad$ MVR & 29 & 67 \\
$\quad$ Mechanical & 14 & 32 \\
$\quad$ Biologic & & \\
$\quad$ AVR plus MVR & 27 & 67 \\
$\quad$ Mechanical & 13 & 32 \\
$\quad$ Biologic & $111 \pm 34^{*}$ \\
Crossclamp time (min) & $142 \pm 47^{*}$ \\
Cardiopulmonary bypass time (min) & \multicolumn{2}{c}{} \\
\hline
\end{tabular}

*Mean \pm standard deviation of the mean.

repairable. In these patients the posterior leaflet was completely detached from the calcified mitral anulus. This detachment was often from commissure to commissure of the mitral valve. The calcium was usually excised in a single block by sharp dissection. A strip of fresh autologous pericardium $2 \mathrm{~cm}$ wide and as long as the distance of mitral anulus to be reconstructed (range 6 to $8 \mathrm{~cm}$ ) was prepared. One of the margins of this strip was sutured to the smooth endocardium of the inflow of the left ventricle and the other margin was sutured to the posterior left atrial wall with a continuous $3-0$ polypropylene suture as shown in Fig. 1. This suture was interrupted at the transition between ventricular and atrial walls. The posterior leaflet of the mitral valve was repaired as needed and then it was reattached to the pericardial patch at the level of the original anulus. An annuloplasty ring (Carpentier* in 4 patients and Durant in 6) was used in every patient. The ring was secured to the anterior leaflet of the mitral valve superiorly and to the pericardial patch and posterior leaflet posteriorly. One patient also required AVR and two patients had CABG.

In nine patients the mitral valve had been previously replaced and after the prosthetic valve was explanted it was deemed that the fibrous tissue underneath the aortic valve was inadequate to secure another prosthetic valve without affecting the function of the aortic valve. In these patients the ascending aorta was opened and through a combined transatrial and transaortic approach a crescentic patch of Dacron fabric (7 patients) or glutaraldehydefixed bovine pericardium ( 2 patients) was secured underneath the aortic valve from fibrous trigone to fibrous trigone with a continuous 2-0 polypropylene suture as shown in Fig. 2. The new prosthetic mitral valve was secured to this patch superiorly and to the native mitral anulus posteriorly. Two patients also needed AVR, two needed tricuspid valve repair, and one had $C A B G$.

In 29 patients the posterior mitral anulus had been damaged by extensive calcification (13 patients), infective

*Baxter Healthcare Corp, Edwards Division, Santa Ana, Calif. $\dagger$ Medtronic, Inc., Minneapolis, Minn. 


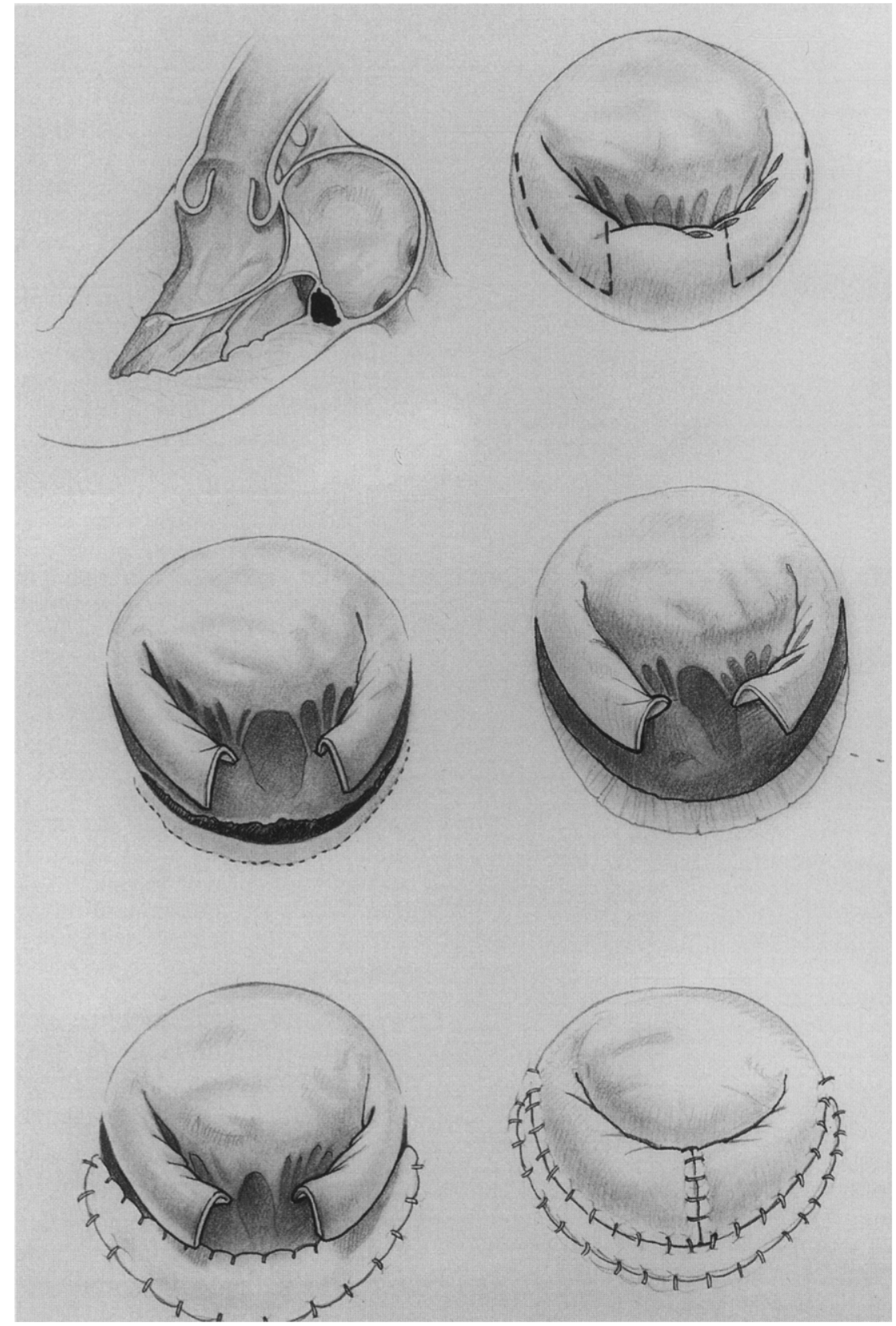

Fig. 1. Reconstruction of posterior mitral anulus and repair of mitral valve.

endocarditis with abscess (10 patients), or acute "spontaneous" rupture of the proximal part of the posterior wall of the left ventricle after MVR (6 patients). The native or prosthetic mitral valve was excised and in cases of abscess or extensive calcification of the mitral anulus, meticulous débridement of the anulus was performed. A semicircular patch of fresh autologous pericardium (19 patients) or glutaraldehyde-fixed bovine pericardium (10 patients) was used for reconstruction of the anulus. The patch was approximately $2 \mathrm{~cm}$ larger than the defect in the mitral anulus. The circular margin of the patch was sutured to the endocardium of the left ventricle with a continuous 3-0 polypropylene suture as shown in Fig. 3. The straight margin was used to secure the new prosthetic mitral valve. In cases of spontaneous rupture of the posterior left ventricular wall and débridement of calcium or abscess with perforation of the atrioventricular groove, the straight margin of the patch was also sutured to the left atrium to seal the perforation completely (Fig. 3). In addition to the MVR, eight patients also had AVR, five had tricuspid valve repair, and three had CABG. 


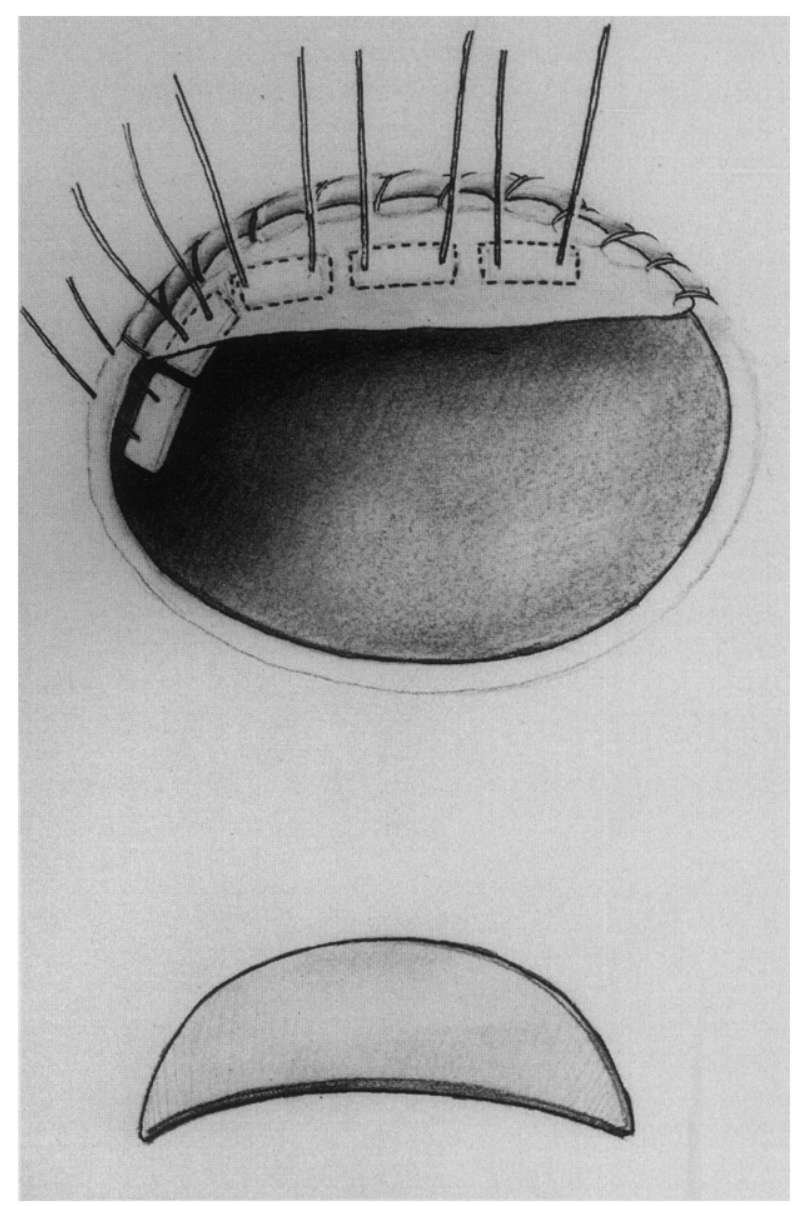

Fig. 2. Reconstruction of superior mitral anulus.

In 25 patients the mitral anulus was damaged in multiple areas and the whole circumference of the anulus was reconstructed as shown in Fig. 4. The anulus had been damaged by endocarditis in 14 patients and by multiple previous MVRs in 11 patients. A strip of fresh autologous pericardium (1 patient) or bovine pericardium (24 patients) $2 \mathrm{~cm}$ wide and 10 to $12 \mathrm{~cm}$ long (the length of the perimeter of the mitral anulus, which can be calculated by multiplying the diameter of the anulus by pi) was sutured to the endocardium of the left ventricle posteriorly and to the fibrous tissue underneath the aortic valve superiorly. The ascending aorta was opened to facilitate the suturing underneath the aortic valve and to prevent damage to its noncoronary leaflet. A prosthetic mitral valve was then sutured to the pericardial patch. To avoid a rocking movement of the prosthesis, no excessive patch material was to be left between the two suture lines. Ten patients also had AVR, five had tricuspid valve repair, and two had CABG.

In 20 patients the fibrous tissue between the aortic and the mitral anuli was damaged by abscess between the aortic and mitral valves ( 4 patients), extensive calcification
(1 patient), and multiple previous AVRs and MVRs (11 patients). In these patients the operation was done through the aortic root and roof of the left atrium. The aortic valve was removed and the aortotomy was extended into the noncoronary sinus of Valsalva in the direction of the mitral valve, which was excised through the aortic root. Bovine pericardium was used to reconstruct the anuli in all patients. In 16 patients a triangular bovine pericardial patch was sutured to each fibrous trigone and to the aortic root as shown in Fig. 5. The prosthetic MV was secured to the native mitral anulus posteriorly and to the base of the triangular pericardial patch superiorly. The roof of the left atrium was closed with a separate bovine pericardial patch by suturing the patch to the margins of the atriotomy and to the triangular patch. The aortic prosthesis was secured to the aortic anulus and triangular pericardial patch. The patch used to close the roof of the left atrium was incorporated in the aortic valve sutures. In four patients the posterior mitral anulus was also damaged and a single bovine pericardial patch was used to reconstruct the whole mitral anulus and aortic root as shown in Fig. 6. All these 20 patients had AVR, 3 had replacement of the ascending aorta, 13 had tricuspid valve repair, and 4 had $C A B G$.

Statistical analysis. Univariate analysis was used to identify factors associated with increased operative mortality; a stepwise logistic regression analysis was applied to statistically significant variables. The Kaplan-Meier method was used to calculate the actuarial survival, the freedom from reoperation, and the freedom from failure of the reconstruction of the mitral anulus. BMDP statistical software (BMDP Statistical Software, Inc., Los Angeles, Calif.) was used to perform these analyses.

\section{Results}

There were eight operative deaths for an overall operative mortality rate of $8.6 \%$. Three patients died in the operating room ( 2 because of technical problems related to the procedure and 1 because of myocardial infarction); four patients died of intractable congestive heart failure 4 to 17 weeks after operation in the intensive care unit; one patient died of multiple organ failure. All deaths but one occurred in patients who were in shock before the operation and had had previous cardiac operations. Five of the patients who died had active prosthetic valve endocarditis, two had had AVR and MVR twice before, and one had rupture of the posterior wall of the left ventricle after MVR.

Postoperative complications were common: 13 patients required reexploration of the mediastinum because of bleeding, 15 required a permanent transvenous pacemaker, one had a perioperative stroke, and 4 needed temporary renal dialysis. Five patients required reoperation in the first postoperative year, 4 because of new endocarditis and 1 because of patch dehiscence. They all survived reoperation. 


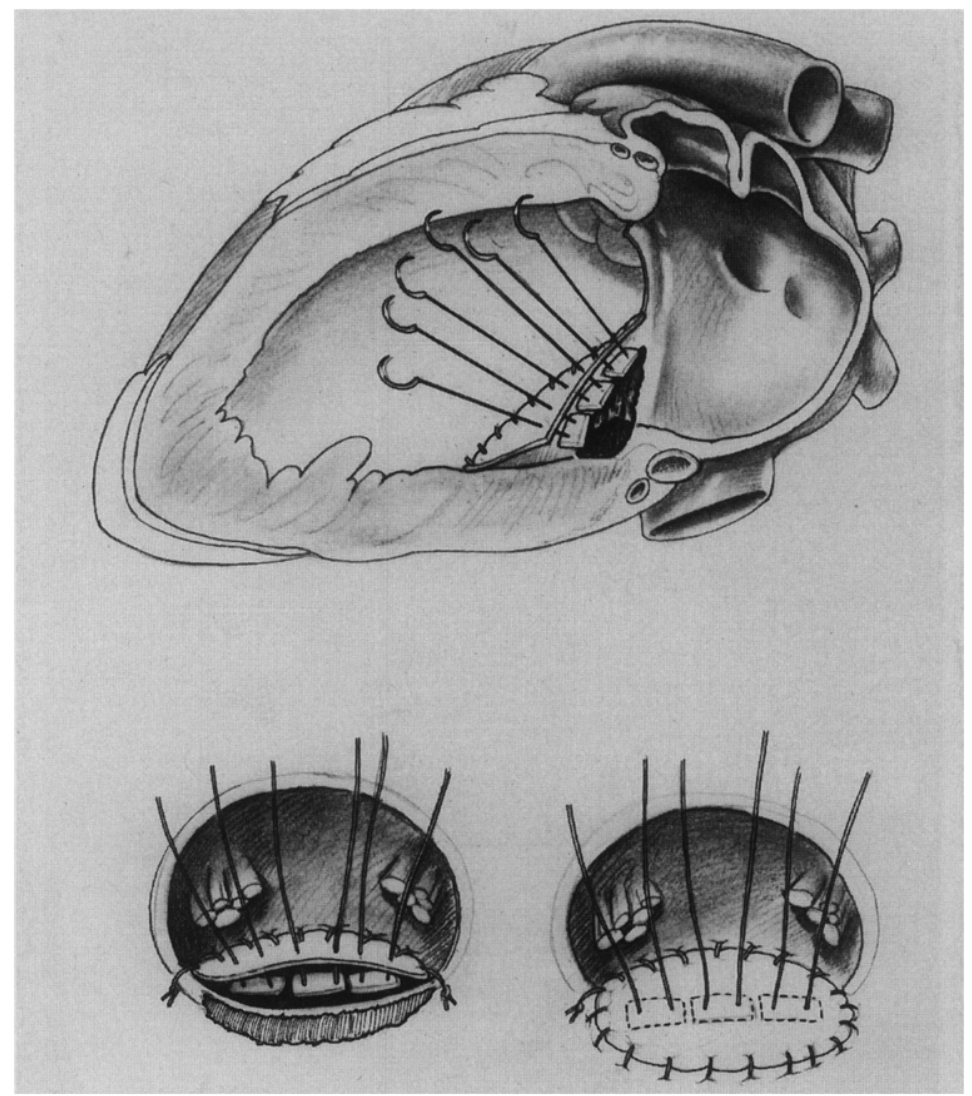

Fig. 3. Reconstruction of posterior mitral anulus.

Univariate analysis revealed that NYHA functional class IV $(p<0.04)$, shock $(p<0.001)$, and prosthetic valve endocarditis $(p<0.004)$ were associated with higher operative mortality. By multivariate analysis only shock $(p<0.005)$ and prosthetic valve endocarditis $(p<0.01)$ were independent predictors of operative mortality.

Patients were followed up from 12 to 96 months, with a mean of 30 months. No patient was lost to follow-up. There have been 18 late deaths: 14 cardiac (valve related 3, arrhythmias 2, myocardial infarction 1, and heart failure 4) and 4 noncardiac. Fig. 7 shows the actuarial survival of all patients. At 5 years the actuarial survival was $68 \% \pm 6 \%$.

Three patients required late reoperation because of hemolysis as a result of paravalvular leakage in two and degeneration of a bioprosthetic valve in one. The mitral anulus had to be re-reconstructed in the first two patients and a rather simple second MVR without reconstruction of the mitral anulus was possible in the third patient. Fig. 8 shows the actuarial freedom from early and late reoperations. Fig. 9 shows the actuarial freedom from failure of the reconstructive procedure in the mitral anulus. Anticoagulant-related hemorrhage and thromboembolic complications have been uncommon in these patients: only one had a hemorrhagic complication and four had thromboembolism (stroke in 1 and transient ischemic attack in 3). At the most recent follow-up, clinical assessment indicated that $52 \%$ of the patients are in NYHA class I, 24\% in class II, and $24 \%$ in class III. Doppler echocardiographic studies have shown normal prosthetic valve function and intact mitral anulus repair in all patients.

\section{Discussion}

Extensive calcification of the mitral anulus presents a formidable challenge during mitral valve operations. Degenerative calcification of the mitral anulus is often limited to the posterior part of the anulus but it may extend into the myocardium, and in patients with myxomatous mitral valve disease it can also involve the papillary muscles. ${ }^{10-12}$ Unlike the calcification that occurs in rheumatic mitral valves, which involves primarily the leaflets, degenerative calcification affects primarily the mitral anu- 


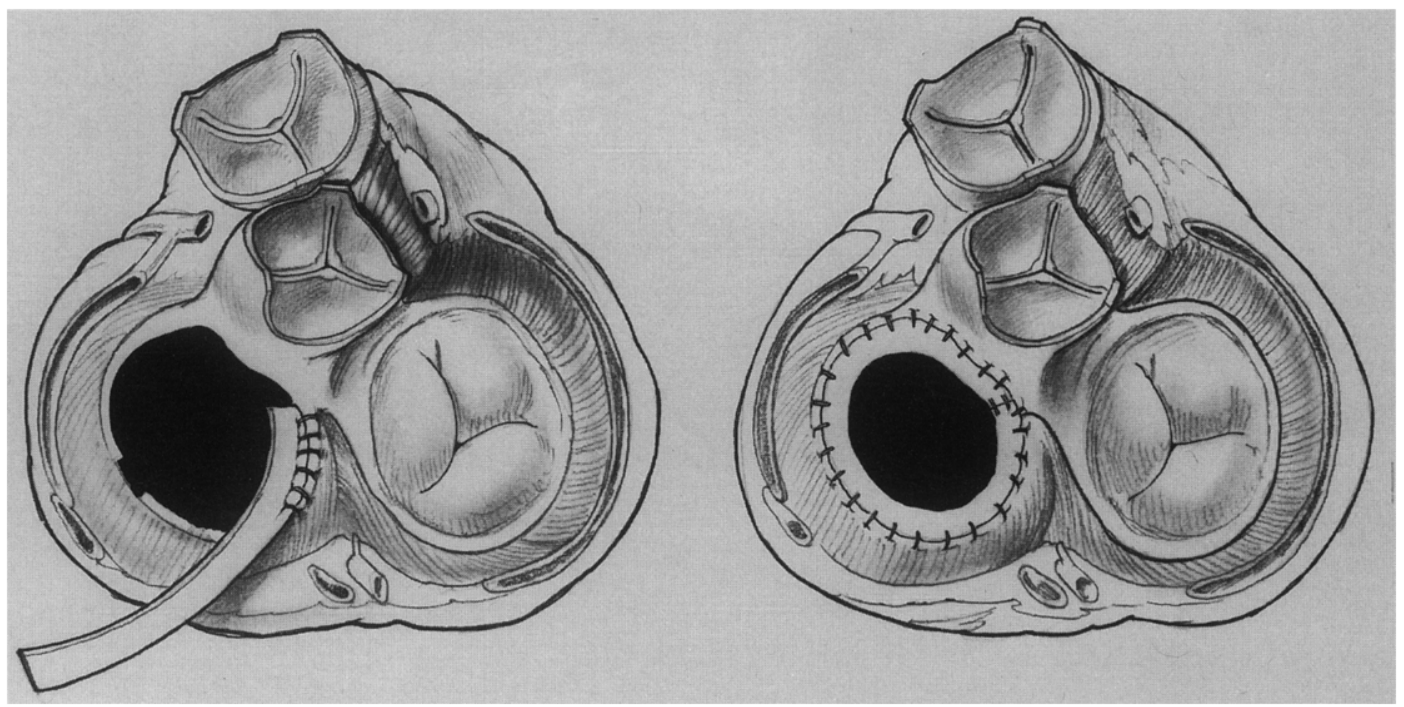

Fig. 4. Reconstruction of entire mitral anulus.

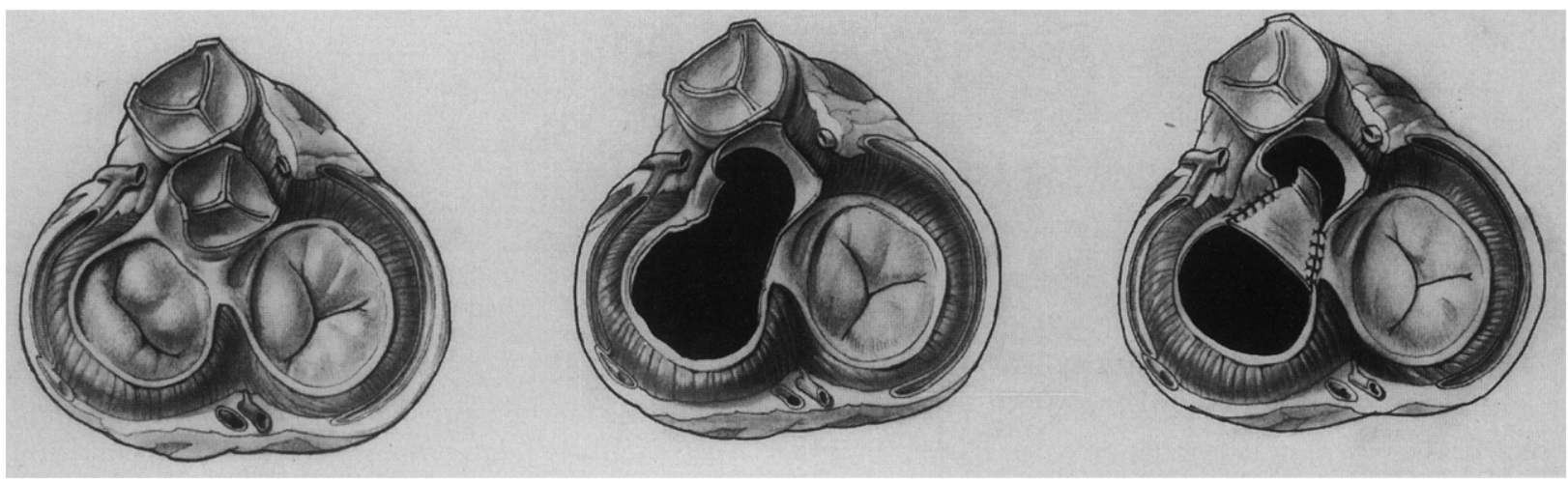

Fig. 5. Reconstruction of fibrous anulus between the aortic and mitral valves.

lus. ${ }^{10,12}$ Thus mitral valve repair is possible in these patients. In our series of 24 patients with calcification of the mitral anulus, 14 had degenerative calcification and the mitral valve was repaired in 10 and replaced in 4 . The remaining 10 patients had already had MVR before being referred to us for a second mitral valve operation because of prosthetic valve dehiscence or malfunction. Most surgeons do not excise the calcium as we have described. ${ }^{8,9}$ The preferred method appears to be partial débridement of the calcium and fixation of a prosthetic mitral valve in the calcified mitral anulus with large sutures with pledgets. ${ }^{1,13}$ Cammack, Edie, and Edmunds ${ }^{1}$ reported a series of 11 patients with degenerative calcification of the mitral anulus: repair was feasible in 1 and 3 patients died, one in the operating room and two of ventricular rupture early after operation. Not only is operative mortality high in patients with a heavily calcified mitral anulus but there is also a significant morbidity such as prosthetic valve malfunction (the leaflets or ball may not open and close fully) and dehiscence with paravalvular regurgitation. $^{13-15}$

Abscess of the mitral anulus is not as common as aortic root abscess, but it does occur, particularly in patients with prosthetic mitral valve endocarditis. ${ }^{2,3}$ Antibiotics alone seldom sterilize a paravalvular abscess and operation is necessary. We believe that the procedure of radical resection of the abscess and reconstruction of paravalvular structures with pericardium offers the best chance of cure of the infection. ${ }^{16}$ In our present series of 27 patients with mitral anulus abscess 5 patients died, but none because of failure of the reconstructive procedure. All 5 deaths were caused by multiorgan failure or myocardial failure. 


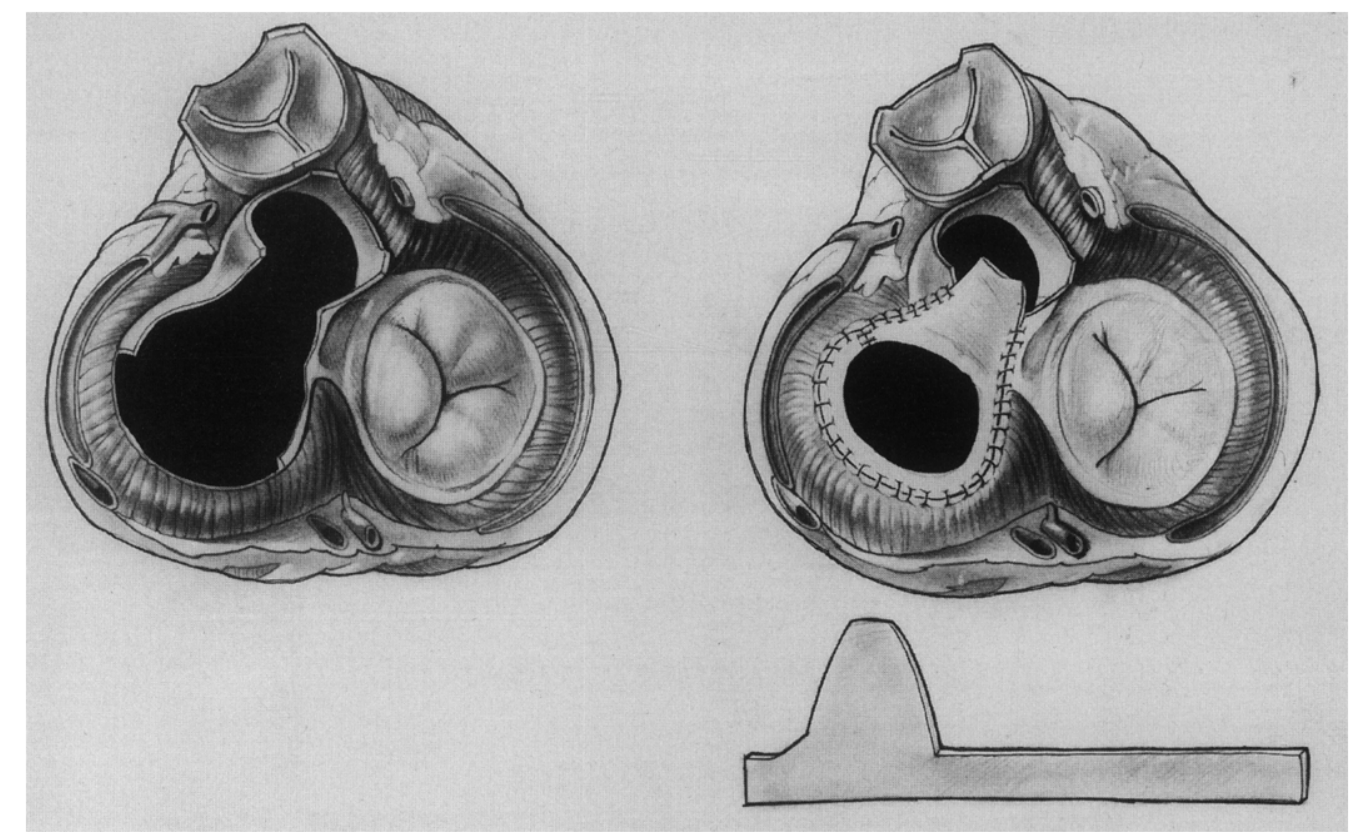

Fig. 6. Reconstruction of aortic and mitral anuli.

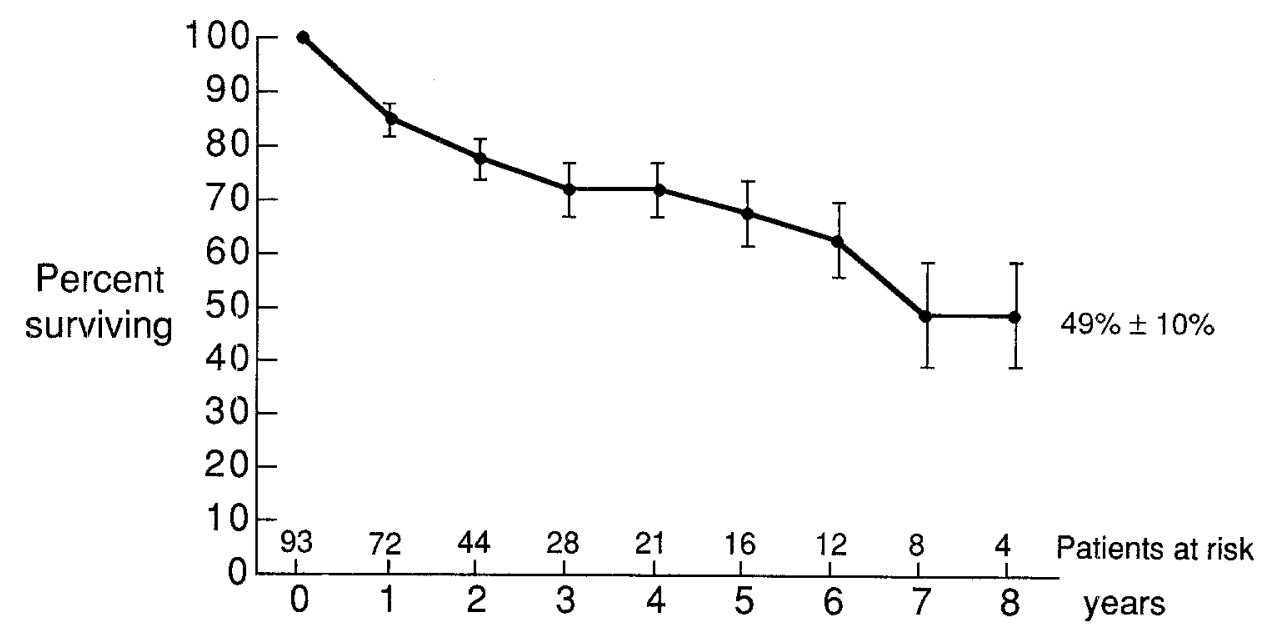

Fig. 7. Actuarial survival after reconstruction of mitral anulus.

Nataf and associates ${ }^{17}$ recently reported their experience with 36 patients in whom the mitral anulus had been destroyed by endocarditis (15 patients) or by calcification ( 20 patients). They secured a prosthetic mitral valve to the left atrial wall by expanding its sewing cuff with a Dacron collar. Eight patients with endocarditis and 5 patients with calcification of the mitral anulus died in the perioperative period, for an overall operative mortality rate of $36 \%$. Of 23 operative survivors, 4 required reopera- tion because of prosthetic mitral valve dehiscence. Thus the operative procedure failed to resolve the problem in almost one half of the patients. What is surprising to us is that the left atrial wall is capable of tolerating ventricular pressures. We would have expected the suture line to tear or the atrial wall to dilate and form an aneurysm. However, these problems do not seem to occur, according to the authors. $^{17}$

In 36 patients of our series of 93, the principal 


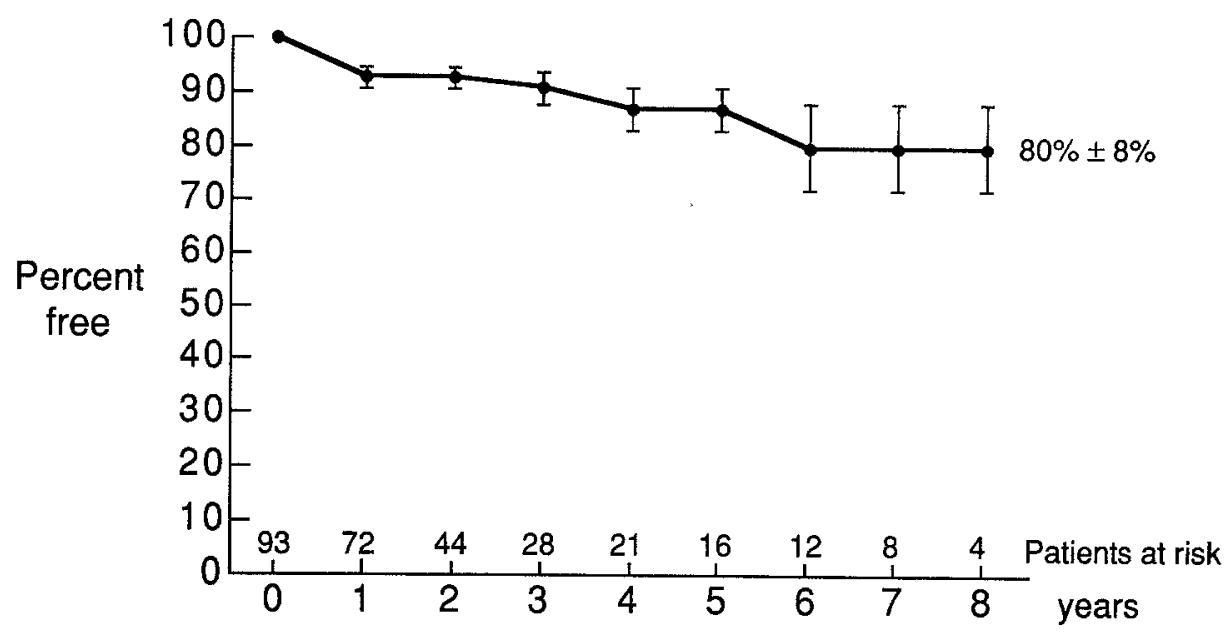

Fig. 8. Actuarial freedom from reoperation.

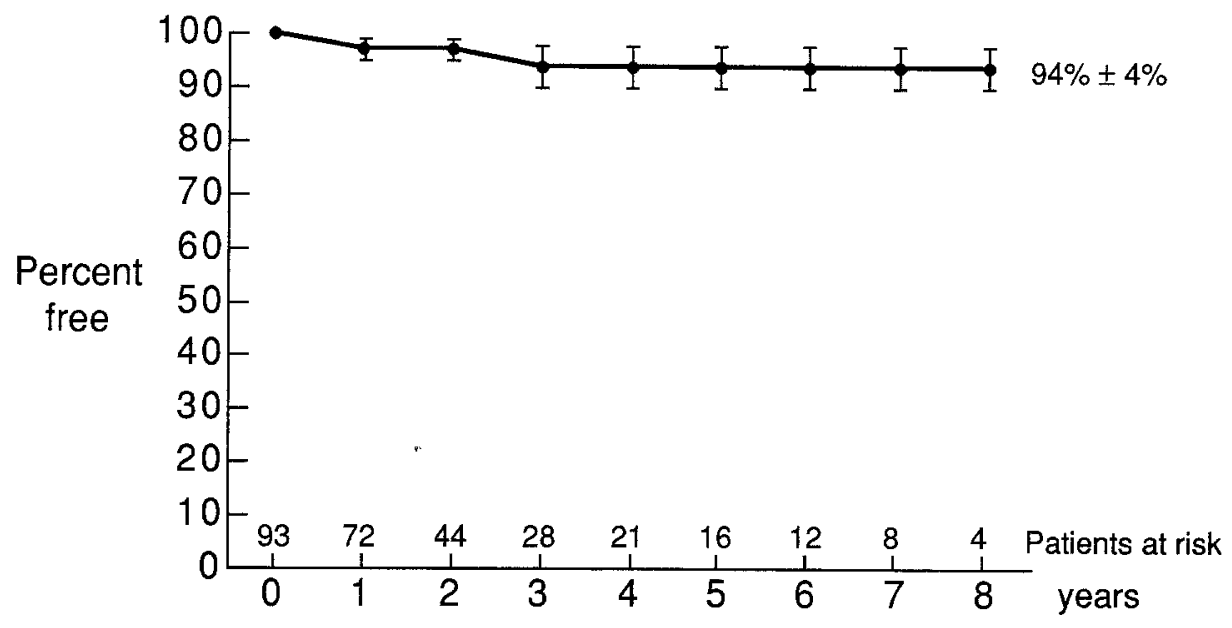

Fig. 9. Actuarial freedom from failure of reconstructive procedure.

indication for mitral anulus reconstruction was damage of the anulus as a result of one or more previous MVRs. The fibrous tissue between the aortic and mitral anuli may be inadequate to secure a new prosthetic mitral valve or the function of the aortic valve may be affected when the prosthetic mitral valve is sutured too close to the aortic anulus. In addition, in patients who need double valve replacement, one prosthetic valve may interfere with the function of the other when there is not enough space between the aortic and mitral anuli. One approach that prevents iatrogenic damage to the mitral anulus when a prosthetic mitral valve is explanted is to remove all sutures first and then gently separate the sewing ring of the prosthesis from the mitral anulus. Another method is to cut into the sewing ring of the prosthetic valve, leaving part of it attached to the mitral anulus. Once the prosthesis is out, the mitral anulus is carefully débrided from all old sutures and Dacron or Teflon material. However, in certain cases, though extreme care is exercised during explantation of the prosthetic mitral valve, the mitral anulus may not be strong enough to hold the new prosthetic mitral valve or surrounding structures may be damaged during the fixation of the new mitral valve prosthesis. We believe that is one of the reasons reoperative valve operation is associated with higher operative mortality and morbidity than first-time operations. Reconstruction of the mitral anulus makes reoperative mitral valve surgery safer.

Another indication for reconstruction of the mitral anulus is left ventricular rupture after MVR. ${ }^{7}$ 
Although the risk of rupture of the left ventricle after MVR is greatly reduced when the attachments between the papillary muscles and mitral anulus are preserved, ${ }^{18}$ rupture has been reported even after mitral valve repair when the whole apparatus is left in situ. ${ }^{19}$ Left ventricular rupture after MVR has been classified as type I when the tear occurs in the atrioventricular area, type II when it occurs around the papillary muscles, and type III or midventricular rupture when it is located in the center of the space between the atrioventricular groove and the papillary muscles. ${ }^{4}$ Regardless of the site of rupture, the outcome is extremely serious. We have successfully repaired five of six cases of type I rupture after MVR by use of our technique of endocardial patch with fresh autologous pericardium. Celestin and associates $^{20}$ described the cases of two patients with rupture of the posterior wall after MVR who were successfully treated with reconstruction of the mitral anulus as described in this article.

Reconstruction of the mitral anulus has been extremely useful for complex forms of mitral valve disease in our practice. The prosthetic mitral valve can be safely secured in a newly created mitral anulus made of pericardium. We initially used fresh autologous pericardium for reconstruction of the mitral anulus ${ }^{7-9}$ but as our experience increased we began to use glutaraldehyde-fixed bovine pericardium with equally good success. The longest follow-up of patients with mitral anulus reconstruction with bovine pericardium is slightly more than 7 years, and the mitral anulus remains stable without evidence of fatigue or calcification. It is possible that the bovine pericardium will calcify later on. In areas subtended by other structures such as the posterior wall of the left ventricle, we prefer to use fresh autologous pericardium, but in unsupported areas such as the fibrous tissue between the aortic and mitral anuli, we prefer glutaraldehyde-fixed bovine pericardium because we have the impression that it is stronger.

We are indebted to Dr. A. Kerwin and Ms. J. David for their assistance in the preparation of this manuscript.

\section{REFERENCES}

1. Cammack PL, Edie RN, Edmunds LH Jr. Bar calcification of the mitral anulus: a risk factor in mitral valve operation. J Thorac CARdiovasc Surg 1987; 94:399-404.

2. Arnett EN, Roberts WC. Valve ring abscess in active infective endocarditis: frequency, location, and clues to clinical diagnosis from the study of 95 necropsy patients. Circulation 1976;54:140-5.

3. Rocchioccioli C, Chastre J, Lecompte Y, et al. Prosthetic valve endocarditis: the case for prompt surgical management. J Thorac Cardiovasc Surg 1986;92: 784-9.

4. Treasure Rl, Rainer WG, Strevey TE, et al. Intraoperative left ventricular rupture associated with mitral valve replacement. Chest 1974;66:511-4.

5. Lytle BW, Cosgrove DM, Taylor PC, et al. Reoperations for valve surgery: perioperative mortality and determinants of risk for 1,000 patients, 1958-1984. Ann Thorac Surg 1986;42:632-43.

6. Miller DC, Shapiro JN, Stinson EB, Shumway NE. Left ventricular coronary sinus fistula following repeated mitral valve replacement. J THORAC CARDIOVASC SURG 1978;76:43-5.

7. David TE. Left ventricular rupture after mitral valve replacement: endocardial repair with pericardial patch. J Thorac Cardiovasc Surg 1987;93:935-6.

8. David TE, Feindel CM. Reconstruction of the mitral annulus. Circulation 1987;76(Suppl):III102-7.

9. David TE, Feindel CM, Ropchan GV. Reconstruction of the left ventricle with autologous pericardium. J Thorac Cardiovasc Surg 1987;94:710-4.

10. Korn D, DeSanctis RW, Sell S. Massive calcification of the mitral annulus. N Engl J Med 1962;267:900-9.

11. Fulkerson PK, Beaver BM, Auseon JC, Graber HL. Calcification of the mitral annulus. Am J Med 1979; 66:967-77.

12. Geill T. Calcification of the left annulus fibrosus ( 230 cases). Acta Med Scand 1950;138:153-6.

13. Bulkley BH, Morrow AG, Roberts WC. Calcification of the mitral annulus: a late complication of valve replacement with caged-ball prosthesis [Abstract]. Am J Cardiol 1973;31:123.

14. MacVaugh H III, Joyner CR, Johnson J. Unusual complications during mitral valve replacement in the presence of calcification of the annulus. Ann Thorac Surg 1971;11:336-42.

15. Orszulak TA, Schaff HV, Danielson GK, Pluth JR, Puga FJ, Piehler JM. Results of reoperation for periprosthetic leakage. Ann Thorac Surg 1983;35: 584-9.

16. David TE, Bos J, Christakis GT, Brofman PR, Wong D, Feindel CM. Heart valve operations in patients with active infective endocarditis. Ann Thorac Surg 1990;49:701-5.

17. Nataf P, Pavie A, Jault F, Bors V, Cabrol C, Gandjbakhch I. Intraatrial insertion of a mitral prosthesis in a destroyed or calcified mitral annulus. Ann Thorac Surg 1994;58:163-7.

18. Miller DW, Johnson DD, Ivey TD. Does preservation of the posterior chordae tendineae enhance survival during mitral valve replacement? Ann Thorac Surg 1979;28:22-7. 
19. Izzat MB, Smith GH. Rupture of left ventricle after mitral valve repair: case report and new technique of repair. Br Heart J 1993;69:366-7.

20. Celestin D, Nunes L, Aguado MG, et al. Intraventricular patch repair of ventricular rupture following mitral valve replacement. Ann Thorac Surg 1982;33: 638-40.

\section{Discussion}

Dr. Lawrence I. Bonchek (Lancaster, Pa.). After Dr. David first told me about his early favorable experiences with the use of pericardium some years ago, I began to use it with increasing frequency to assist in the management of certain awkward technical situations. Just to emphasize that this technique can be used even by surgeons outside Toronto, such as me, who do not have as extensive an experience with complex diseases of the valve, I would like to describe several circumstances in which I have used pericardium.

We, too, have found it ideal for management of endocarditis of the aortic root with extension into the mitral anulus and have used pericardium to reattach the anterior mitral leaflet by working through the open aorta and the left atrium. I would emphasize that it is remarkable how easy it is to do this even though the problem appears to be confined to the mitral anulus; exposure through the aortic root makes the situation quite easy to see, whereas exposure through the left atrium can be frustrating. Pericardium can also be used effectively to facilitate mitral valve repair and replacement in the calcified anulus.

The technique I have used is an outgrowth of the Toronto technique for the use of pericardium to cover defects in the mitral anulus. In patients with heavy calcification that one does not wish to débride, the calcium can simply be covered with pericardium. After the pericardium is attached to the ventricular myocardium and to the left atrial wall, it is a simple matter to attach a portion of the prosthetic sewing ring, or the mitral leaflet in case of a repair, to the midportion of the pericardial patch. We use a slightly different technique of not placing the sutures until the patch has been completely sewn in place rather than of placing the sutures through the patch as the authors illustrated.

When annular tissue is calcified or deficient, pericardium can also be used to close an acute intraoperative perivalvular leak by using a crescent-shaped patch between the sewing ring and the left atrial wall. The postoperative echocardiogram may show inevitable bulging of the patch, but no leak and no interference with normal hemodynamics.

Finally, I have also used pericardium in one patient with intraoperative bleeding from the high posterior left ventricular wall after MVR, a so-called type I rupture. The problem was resolved completely by excising the prosthesis, sewing a pericardial patch over the defect in the posterior ventricular myocardium, and incorporating the upper edge of the patch into the annular sutures. In keeping with cost-containment concerns, the same prosthesis was, of course, reinserted thereafter. The patient was discharged from the hospital 1 week after operation after an entirely uneventful recovery.

All of these reconstructions were accomplished with autologous pericardium soaked in glutaraldehyde for approximately 8 minutes. My question to the authors is to ask for a comment about bovine pericardium, which they seem to prefer, as opposed to autologous pericardium, which is usually available, is free, and can be treated with glutaraldehyde to lessen concerns about its strength.

Dr. Feindel. Certainly we use bovine pericardium in the case of multiple repeat operations when we believe that there is less availability of the autologous pericardium. I quite agree that autologous pericardium is cheaper, and we tend to use it for the smaller patches. However, for large reconstructions, especially when the fibrous central body between the aortic and mitral valves has been destroyed, we find it easier to work with bovine pericardium.

Dr. Alain F. Carpentier (Paris, France). There is no question in my mind that this is an important paper, and the use of pericardium is extremely important. What we have shown is that when one wishes to reach an ideal repair, this is what can be done rather than leaving some calcium. I would like to point out that pericardium is a useful tool that must be used and that there is a place to use it.

I believe that, if one is going to use pericardium, it is preferable to use autologous pericardium, not only because it is cheaper, but also because it is a better material. The question then arises whether to use glutaraldehydetreated autologous pericardium or fresh autologous pericardium. I think when there is no concern about the possibility of stretching or shrinkage, particularly in the case of endocarditis, it is much better to use fresh pericardium, because it is more resistant to infection. When pericardium is used to repair a part of the valve, glutaraldehyde-treated pericardium is preferable.

Dr. David. We do favor autologous pericardium whenever the patch is lying against living tissue, such as the ventricular or atrial wall. However, if the patch is freestanding, like the fibrous structure between the aortic and mitral valves, we prefer to use glutaraldehyde-fixed pericardium. 